\title{
Immobilization of flavan-3-ols onto sensor chips to study their interactions with proteins and pectins by SPR
}

\author{
Aude A. Watrelot ${ }^{\mathrm{a}, \mathrm{b}, *}$, Dong Tien Tran ${ }^{\mathrm{c}, \mathrm{d}}$, Thierry Buffeteau ${ }^{\mathrm{c}}$, Denis Deffieux ${ }^{\mathrm{c}, \mathrm{d}}$, \\ Carine Le Bourvellec $^{\mathrm{a}, \mathrm{b}}$, Stéphane Quideau ${ }^{\mathrm{c}, \mathrm{d}}$, Catherine M.G.C. Renard ${ }^{\mathrm{a}, \mathrm{b}}$ \\ a INRA, UMR408 Sécurité et Qualité des Produits d'Origine Végétale, Domaine St Paul, Site Agroparc, 84914 Avignon, France \\ ${ }^{\mathrm{b}}$ Université d'Avignon, UMR408 Sécurité et Qualité des Produits d'Origine Végétale, F-84000 Avignon, France \\ ' Université de Bordeaux, Institut des Sciences Moléculaires (UMR-CNRS 5255), 351 cours de la Libération, 33405 Talence, France \\ d Institut Européen de Chimie et Biologie (IECB), 2 rue Robert Escarpit, 33607 Pessac, France
}

Keywords:

Polyphenol

Polysaccharide

Procyanidin

Bovine serum albumin

Poly-L-proline

Surface plasmon resonance

\begin{abstract}
A B S T R A C T
Interactions between plant polyphenols and biomacromolecules such as proteins and pectins have been studied by several methods in solution (e.g. isothermal titration calorimetry, dynamic light scattering, nuclear magnetic resonance and spectrophotometry). Herein, these interactions were investigated in real time by Surface Plasmon Resonance (SPR) analysis after immobilization of flavan-3-ols onto a sensor chip surface. (-)-epicatechin, (+)-catechin and flavan-3-ol oligomers with an average degree of polymerization of 2 and 8 were chemically modified using $N$-(2-(tritylthio)ethyl)propiolamide in order to introduce a spacer unit onto the catecholic B ring. Modified flavan-3-ols were then immobilized onto a carboxymethylated dextran surface (CM5). Immobilization was validated and further verified by evaluating flavan-3-ol interaction with bovine serum albumin (BSA), poly-L-proline or commercial pectins. BSA was found to have a stronger association with monomeric flavan-3-ols than oligomers. SPR analysis of selected flavan-3-ols immobilized onto CM5 sensor chips showed a stronger association for citrus pectins than apple pectins, regardless of flavan-3-ol degree of polymerization.
\end{abstract}

\section{Introduction}

Flavan-3-ols belong to a large and diverse family of plant secondary metabolites, the polyphenolic flavonoids. This class of plant phenolics has widespread interest to food processors and is of particular interest for their potential health benefits. Flavan-3-ol oligomers and polymers, called proanthocyanidins, form the socalled "condensed tannins". Tannins have long been recognized for their capacity to interact with and precipitate proteins or polysaccharides. This ability to interact with macromolecules has

Abbreviations: SPR, surface plasmon resonance; CM5, carboxymethyl dextran; BSA, bovine serum albumin; PLP, ploy-L-proline; DP, degree of polymerization; ITC, isothermal titration calorimetry; EPI, (-)epicatechin; CAT, (+)-catechin; DP2, flavan3-ols dimer; DP8, flavan-3-ols oligomer with a degree of polymerization of 8; STrt, linker with trityl group; $\mathrm{SH}$, linker with thiol group; ATR, attenuated total reflection; RU, resonance units.

* Corresponding author at: INRA, UMR408 Sécurité et Qualité des Produits d'Origine Végétale, Domaine St Paul, Site Agroparc, 84914 Avignon Cedex 9, France.

E-mail addresses: aude.watrelot@avignon.inra.fr, watrelotaude@yahoo.fr

(A.A. Watrelot). implications in food chemistry (e.g. red wine fining and astringency) [1]. Insight into the mechanism of interaction between tannins and macromolecules has applications in food and beverage production and potentially in human health.

Flavan-3-ols are abundant in beverages (e.g. wine, tea, cider) and fruits (e.g. apple, grape, nuts) [2]. The term "procyanidins" specifically designates oligo/polymers of (+)-catechin and (-)epicatechin. Procyanidins are characterized by the type of linkages between those flavan-3-ol building blocks and the number of such constitutive units or degree of polymerization (DP) [3]. Procyanidins from apple are an interesting model due to their structural homogeneity combined with their variation in size. They are composed of (-)-epicatechin units that are linked together through their C4 and C8 positions with a DP of up to 50 [4], where in some instances (+)-catechin can be found as a terminal unit. Such flavonoid oligo/polymers are able to bind to biomacromolecules such as proteins [2] or polysaccharides, including notably pectins [5].

Pectins are plant polysaccharides, which are mainly found in the middle lamella and primary cell wall. Their backbone chains are characterized by partially methyl esterified and acetylated 
galacturonic acid units (homogalacturonan), and rhamnose units to which are linked neutral sugar side chains (rhamnogalacturonans) [6].

Interactions between polyphenols and biomacromolecules, mostly proteins, have been studied in solution by various analytical techniques such as isothermal titration calorimetry (ITC), dynamic light scattering or nuclear magnetic resonance spectroscopy, for understanding the strength and equilibrium/energy parameters of interactions [5,7-12]. Only a few studies have been performed by immobilizing one of the two compounds on a sensor surface for determining the affinity strength by Surface Plasmon Resonance (SPR). SPR is an optical-based real-time detection method which allows for the analysis of biomolecular recognition at surfaces between an immobilized ligand and an analyte. For example, salivary proteins have been immobilized onto a dextran SPR sensor chip for characterizing the interaction between protein and $\beta$-pentagalloylglucose, a common precursor of gallotannins [13-15]. Conversely, as polyphenols are known to interact in a nonspecific manner with proteins, other studies have chosen to immobilize polyphenols such as chemically modified vescaline and biotinylated vescalagin onto modified dextran and streptavidin-coated sensor chips, respectively, for examining their interaction with proteins such as topoisomerase II $\alpha$ and filamentous actin [16]. The literature is very scarce concerning the SPR analysis of protein and polysaccharide interaction with polyphenols. Joergensen et al. [17] have studied associations between pectins and protein immobilized onto a gold sensor chip, while Seo et al. [18] have worked on interactions between carbohydrates immobilized onto a gold surface and lectins. Moreover, Hayashi et al. [19] have shown higher affinity between $\beta$-cyclodextrin immobilized onto a carboxymethylated dextran sensor chip and (-)-epigallocatechin-3-O-gallate and (-)-epicatechin-3-O-gallate than non-galloylated (-)-epigallocatechin and (-)-epicatechin. In our study, the flavan-3-ol monomer/oligomers were immobilized onto carboxymethylated dextran sensor chips in order to minimize non-specific interactions between polyphenols and pectins or proteins, for the first time.

The aim of this study was: first, to define the appropriate chemical method for the immobilization of flavan-3-ol monomers, dimers and oligomers onto a SPR sensor chip; second, to analyze qualitatively the parameters of interactions of these flavonoids and proteins or pectins by SPR and third, to compare with interactions already observed in solution.

\section{Material and methods}

\subsection{Chemicals}

Unless specified, all chemicals used for chemical modification and (+)-catechin, (-)-epicatechin, apple and citrus pectins, bovine serum albumin (BSA) and poly-L-proline (PLP) were purchased from Sigma-Aldrich (Germany). Propiolic acid was purchased from Fluka Chemica (Germany). Sodium hydroxide, magnesium sulfate, sodium bicarbonate and hydrochloric acid were purchased from VWR (France). tert-butanol was purchased from Acros Organics (Geel, Belgium), $C \mathrm{CDCl}_{3}$, DMSO- $d_{6}$ and acetone- $d_{6}$ used for NMR analysis were purchased from Eurisotop (France).

\subsection{Procyanidin preparation and characterization}

Procyanidins of DP2 and DP8 were extracted from 'Kermerrien' and 'Golden delicious' apple parenchyma, respectively, and were characterized as described by Watrelot et al. (Table 1) [20]. The DP2 contained 91\% of (-)-epicatechin and 9\% of (+)catechin. This fraction contained $>90 \%$ polyphenols and included the dimers B2 $((-)$-epicatechin- $(4 \beta \rightarrow 8)-(-)$-epicatechin, $85 \%)$ and B1 ( $(-)$-epicatechin- $(4 \beta \rightarrow 8)-(+)$-catechin, $15 \%)$. The DP8 fraction was determined to be $83 \%$ polyphenolic and was composed of $(-)$ epicatechin (86\%) and (+)-catechin (14\%) only as terminal units [20].

\subsection{Pectin characterization}

Commercially available apple and citrus pectins were characterized by their galacturonic acid and neutral sugar content determined by gas chromatography as well as their partition coefficient evaluated by high performance size exclusion chromatography, as described by Watrelot et al. [5]. The pectin compositions are shown in Table 2. Both pectins differed in neutral sugars content. Citrus pectins were characterized by a higher rhamnose $(2.6 \% \mathrm{w} / \mathrm{w})$ and galactose $(18.3 \% \mathrm{w} / \mathrm{w})$ content than in apple pectins ( $1.6 \%$ and $11.6 \% \mathrm{w} / \mathrm{w}$, respectively), while glucose content was higher in apple pectins $(8.3 \% \mathrm{w} / \mathrm{w})$ than in citrus pectins $(4.4 \%$ $\mathrm{w} / \mathrm{w})$.

\subsection{Modification of flavan-3-ols}

2-[(Triphenylmethyl) thio]ethanamine (CAS number: 1095-858 ) was prepared by an adaption of the procedure reported by Liu et al. [21] To a stirred solution of 2-mercaptoethylamine hydrochloride (1.1 eq.) in anhydrous dichloromethane $(4 \mathrm{~mL})$ at $0{ }^{\circ} \mathrm{C}$ under argon atmosphere was added dropwise trifluoroacetic acid (TFA, $1.6 \mathrm{~mL}$ ), followed by chlorotriphenylmethane (1 eq.). The reaction mixture was stirred for $2 \mathrm{~h}$ at $0{ }^{\circ} \mathrm{C}$, then concentrated and diluted with $\mathrm{CHCl}_{3}(5 \mathrm{~mL})$. The solution was stirred vigorously, mixed with $3 \mathrm{M} \mathrm{NaOH}(8 \mathrm{~mL})$ at room temperature for $1 \mathrm{~h}$. The resulting suspension was then extracted with $\mathrm{CHCl}_{3}(3 \times 60 \mathrm{~mL})$, and the combined organic layers were washed with brine $(3 \times 30 \mathrm{~mL})$, dried over $\mathrm{MgSO}_{4}$, filtered and evaporated to dryness to afford the desired product as a yellowish solid in quantitative yield without any purification (spectroscopic data in supporting information).

$\mathrm{N}$-(2-[(triphenylmethylthio]ethyl) propiolamide was prepared by an adaptation of the procedure reported by Shiu et al. [22] To a stirred solution of propiolic acid (4 eq.) and 4(dimethylamino) pyridine (DMAP, 0.4 eq.) in anhydrous $\mathrm{CH}_{2} \mathrm{Cl}_{2}$ $(3 \mathrm{~mL})$ at $0^{\circ} \mathrm{C}$ under argon atmosphere was added dropwise $N, N^{\prime}-$ diisopropylcarbodiimide (DIC, 5 eq.). To the resulting solution was added a solution of 2-[(triphenylmethyl) thio]ethanamine (1 eq.) in anhydrous $\mathrm{CH}_{2} \mathrm{Cl}_{2}(2 \mathrm{~mL})$. The resulting suspension was allowed to warm up slowly and was then stirred at room temperature for $20 \mathrm{~h}$ under argon. After removing the white precipitate by filtration and diluting with $\mathrm{CHCl}_{3}(90 \mathrm{~mL})$, the resulting solution was washed with $0.5 \mathrm{M} \mathrm{HCl}(10 \mathrm{~mL})$, aqueous saturated $\mathrm{NaHCO}_{3}$ $(10 \mathrm{~mL})$ and brine $(20 \mathrm{~mL})$, dried over $\mathrm{MgSO}_{4}$, filtered and evaporated. The residue was purified by column chromatography, eluting with cyclohexane/EtOAc $(8: 2 ; \mathrm{v} / \mathrm{v})$ to furnish the desired product as a yellowish solid in $43 \%$ yield (spectroscopic data in supporting information).

According to the procedure described by Ariza et al. [23], to a stirred solution of (+)-catechin, (-)-epicatechin, dimer DP2 or oligomers DP8 (1 eq.) in a mixture of anhydrous DMF $(1 \mathrm{~mL})$ and tert-butanol $(1 \mathrm{~mL})$ were added $\mathrm{N}$-(2-(tritylthio) ethyl) propiolamide ( 1.1 eq. for monomer and dimer and 3 eq. for oligomers) and $N, N$-dimethylaminopyridine ( 1.5 eq. for monomer and dimer and 4.5 eq. for oligomers). The reaction mixture of monomers was heated at $40^{\circ} \mathrm{C}$ under an argon atmosphere for $24 \mathrm{~h}$ and $52 \mathrm{~h}$ for dimer; while reaction mixture of oligomers was heated at $60^{\circ} \mathrm{C}$ under an argon atmosphere for 5 days. The solvents and volatiles were then evaporated at $50^{\circ} \mathrm{C}$. The crude mixture of monomers was purified by column chromatography, eluting with $\mathrm{CH}_{2} \mathrm{Cl}_{2}$ to remove impurities, and then with $\mathrm{CH}_{2} \mathrm{Cl}_{2}$ /acetone $(8: 2 ; \mathrm{v} / \mathrm{v})$, 
Version définitive du manuscrit publiée dans / Final version of the manuscript published in :

Applied Surface Science (2016), Vol. 371, p. 512-518, DOI: 10.1016/j.apsusc.2016.03.002

Journal homepage : www.elsevier.com/locatelapsusc

Table 1

Characterization of procyanidins DP2 and DP8 (mg/g of dry matter) (data from Watrelot et al. [5]).

\begin{tabular}{|c|c|c|c|c|c|c|c|c|}
\hline & \multirow[t]{3}{*}{$\mathrm{DPn}$} & \multicolumn{3}{|c|}{ Procyanidins } & \multicolumn{2}{|c|}{ Dihydrochalcones } & \multicolumn{2}{|c|}{ Hydroxycinnamic acids } \\
\hline & & \multirow{2}{*}{$\begin{array}{c}\text { Extension } \\
\text { EPI }\end{array}$} & \multicolumn{2}{|c|}{ Terminal } & \multirow[t]{2}{*}{ PLZ } & \multirow[t]{2}{*}{ XPL } & \multirow[t]{2}{*}{$\mathrm{CQA}$} & \multirow[t]{2}{*}{$\overline{P C Q}$} \\
\hline & & & EPI & $\overline{\text { CAT }}$ & & & & \\
\hline $\mathrm{DP} 2$ & 2 & 464 & 333 & 79 & 0 & 0 & 8 & 0 \\
\hline DP8 & 8 & 562 & 64 & 21 & 1 & 0 & 25 & 1 \\
\hline$S D$ & 0.5 & 43.4 & 1.1 & 0.4 & 0.1 & nd & 7.1 & nd \\
\hline
\end{tabular}


coumaroylquinic acid; SD: pooled standard deviation.

Table 2

Characterization of commercial pectins from apple and citrus: sugar composition ( $\mathrm{mg} / \mathrm{g}$ ) and partition coefficient ( $\mathrm{K}_{\mathrm{av}}$ ) (data from Watrelot et al., [5]).

\begin{tabular}{|c|c|c|c|c|c|c|c|c|c|c|}
\hline & Rha & Fuc & Ara & Xyl & Man & Gal & Glc & GalA & $\mathrm{MeOH}(\mathrm{DM} \%)$ & $\mathrm{K}_{\mathrm{av}}$ \\
\hline Apple pectins & 12 & - & 20 & 8 & 1 & 88 & 63 & 564 & $74(73)$ & 0.02 \\
\hline Citrus pectins & 20 & 1 & 21 & 4 & - & 138 & 33 & 535 & 77 (79) & 0.04 \\
\hline$S D$ & 1.4 & 0.5 & 0.4 & 0.2 & 0.4 & 1.5 & 0.8 & 10.3 & $1.8(0.02)$ & - \\
\hline
\end{tabular}

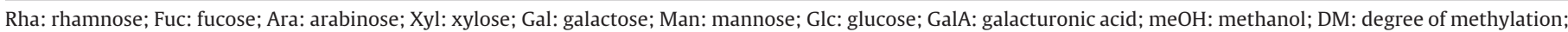
SD: pooled standard deviation.

to furnish a diastereoisomeric mixture of the expected products, named CAT-STrt and EPI-STrt in $48 \%$ and $53 \%$ yield respectively (spectroscopic data in supporting information). The crude mixtures of dimer and oligomer were triturated in $\mathrm{CH}_{2} \mathrm{Cl}_{2}$ to obtain the expected products named DP2-STrt (55\% yield) and DP8-STrt (spectroscopic data in supporting information).

Detritylation was carried out by an adaption of the procedure reported by Basit et al. [24]. To solutions of the flavan-3-ols-STrt (1 eq.) in anhydrous $\mathrm{CH}_{2} \mathrm{Cl}_{2}(1 \mathrm{~mL})$ were added trifluoroacetic acid (5 eq.) and triethylsilane (5 eq.), and the resulting solutions were stirred for $4 \mathrm{~h}$ at room temperature. The solvent and volatiles were then evaporated and the crude products were successively triturated in $\mathrm{CHCl}_{3}(2 \mathrm{~mL})$ and petroleum ether $(10 \times 1 \mathrm{~mL})$ and further dried under vacuum to furnish the expected compounds as yellowish plastics, named CAT-SH (92\% yield), EPI-SH (75\% yield), B2-SH (78\% yield) and DP8-SH (spectroscopic data in supporting information). These compounds reacted positively with Ellman's reagent (5,5'-dithio-bis-(2-nitrobenzoic acid)), thus confirming the presence of free thiols. All modification steps were monitored by NMR spectroscopy (300 MHz) using samples in acetone-d6 or DMSO-d6.

\subsection{Surface plasmon resonance experiments}

All surface plasmon resonance (SPR) experiments were performed using a Biacore ${ }^{\mathrm{TM}} 3000$ biosensor (Biacore, GE Healthcare, Uppsala, Sweden). The sensor possessed a microfluidic cartridge that provides four separate channels for different assays simultaneously. All measurements were performed at $23^{\circ} \mathrm{C}$ in HBS-EP running buffer from GE Healthcare (0.01 M HEPES pH 7.4, $0.15 \mathrm{M}$ $\mathrm{NaCl}, 3$ mM EDTA, 0.005\% surfactant P20). $1 \mathrm{nM}$ flavan-3-ol-SH was dissolved in HBS-EP buffer with $5 \% \mathrm{v} / \mathrm{v}$ acetic acid and then filtered $(0.45 \mu \mathrm{m})$ before injection.

\subsubsection{Immobilization onto CM5 surface}

Carboxymethyldextran sensorchips (CMD 200m, Xantec, Duesseldorf, Germany) were used for immobilization of flavan-3-ol-SH according to the thiol coupling protocol from GE Healthcare. The baseline was stabilized for $300 \mathrm{~s}$ with HBS-EP buffer at $5 \mu \mathrm{L} / \mathrm{min}$. Then $10 \mu \mathrm{L}$ of EDC $(0.2 \mathrm{M}) / \mathrm{NHS}(0.05 \mathrm{M})$ were injected, followed by $20 \mu \mathrm{L}$ of $80 \mathrm{mM}$ 2-(2-pyridinyldithio)-ethanamine (PDEA) prepared in a $0.1 \mathrm{M}$ borate buffer $\mathrm{pH} 8.5$. Two times of $10 \mu \mathrm{L}$ of $1 \mathrm{nM}$ flavan-3-ol-SH was injected. Then, $20 \mu \mathrm{L}$ of a mixture of $50 \mathrm{mM}$ cystein and $1 \mathrm{M}$ sodium chloride prepared in a $0.1 \mathrm{M}$ sodium acetate buffer $\mathrm{pH} 4.3$ was injected. The reference track was prepared under the same conditions as above but without flavan-3-ol-SH.

\subsubsection{Interaction analysis by $S P R$}

Apple and citrus pectins, BSA and PLP were solubilized at 3, 30 and $300 \mathrm{nM}$ in HBS-EP buffer with $5 \% \mathrm{v} / \mathrm{v}$ acetic acid. Interaction analyses were carried out at a flow rate of $20 \mu \mathrm{L} / \mathrm{min}$. After interaction analysis with pectins or proteins, sensor chips were regenerated by injection of SDS $0.1 \% \mathrm{w} / \mathrm{v}$ solution.

\subsection{ATR experiments}

The ATR spectra of CAT, CAT-SH, DP8, and DP8-SH compounds were recorded with a ThermoNicolet Nexus 670 FTIR spectrometer equipped with a liquid nitrogen cooled narrow-band mercury cadmium telluride (MCT) detector using a Silver-Gate (germanium crystal) ATR accessory (Specac). The electric field of the infrared beam was polarized either perpendicular (s-polarized) or parallel ( $p$-polarized) to the plane of incidence with a $\mathrm{BaF}_{2}$ wire grid polarizer (Specac). Each spectrum was obtained after evaporation of a drop $(20 \mu \mathrm{L})$ of a solution ( $2 \mathrm{mg}$ in $100 \mu \mathrm{L}$ of EtOH), at a resolution of $4 \mathrm{~cm}^{-1}$, by co-adding 500 scans.

\subsubsection{Determination of the optical constants of CAT, CAT-SH,} DP8, and DP8-SH compounds

The optical constants (refractive index $n(\bar{v})$ and extinction coefficient $k(\bar{v})$ of CAT, CAT-SH, DP8, and DP8-SH compounds have been determined from polarized attenuated total reflectance (ATR) spectra, using the interdependence of $n(\bar{v})$ and $k(\bar{v})$ by the Kramers-Kronig relations. Dignam et al. have shown how the Kramers-Kronig relations can be applied to polarized ATR spectra [25]. The in-plane optical constants $\left(\mathrm{n}_{\mathrm{xy}}\right.$ and $\left.\mathrm{k}_{\mathrm{xy}}\right)$ were calculated from the s-polarized ATR spectrum, whereas the out-of-plane optical constants $\left(\mathrm{n}_{\mathrm{z}}\right.$ and $\mathrm{k}_{\mathrm{z}}$ ) were obtained from the $p$-polarized ATR spectrum and the before determined $\mathrm{n}_{\mathrm{xy}}$ and $\mathrm{k}_{\mathrm{xy}}$. Then, the isotropic optical constants of CAT, CAT-SH, DP8, and DP8-SH compounds have been calculated from the in-plane and out-of-plane optical constants using the relations: $\mathrm{n}_{\mathrm{iso}}=\left(2 \mathrm{n}_{\mathrm{xy}}+\mathrm{n}_{\mathrm{z}}\right) / 3$ and $\mathrm{k}_{\mathrm{iso}}=$ $\left(2 \mathrm{k}_{\mathrm{xy}}+\mathrm{k}_{\mathrm{z}}\right) / 3$. 


\section{Results}

\subsection{Flavan-3-ol derivatization}

In order to immobilize flavan-3-ol monomers/oligomers onto sensor chips, a linker bearing a protected thiol group at one of its extremities was synthesized. The other extremity of the linker was bound to the flavan-3-ol catecholic B-ring through a Vilarrasa reaction $[23,26]$. In order to optimize the mobility of flavan-3-ols immobilized onto surfaces, flavan-3-ol catechols were modified by using only one equivalent of the linker per equivalent of flavan-3-ol. Modified flavan-3-ols were then detritylated to release their thiol group(s) (Scheme 1). These reactions performed on monomers and dimers were monitored by ${ }^{1} \mathrm{H}$ and ${ }^{13} \mathrm{C}$ NMR analyses, whereas only ${ }^{1} \mathrm{H}$ NMR analysis was used to follow the appearance and disappearance of trityl groups (between 7.5 and $7 \mathrm{ppm}$ ) on DP8 oligomers. Mid-infrared extinction coefficient $k(\bar{v})$ spectra of a monomer (CAT) and flavan-3-ol oligomers (DP8) were also determined from ATR spectra before and after derivatization in order to confirm the presence of thiolate linkers (Fig. 1). The covalent linkage of flavan-3-ols to the linker via an amide bond was confirmed by the presence of amide I $\left(\nu v_{\mathrm{C}=\mathrm{O}}\right)$ and amide II $\left(\delta_{\mathrm{NH}}+v_{\mathrm{C}-\mathrm{N}}\right)$ modes of the linker at 1655 and $1500 \mathrm{~cm}^{-1}$, respectively were observed for both derivatized molecules (CAT-SH and DP8-SH) whereas these bands were not present in the initial CAT and DP8 spectra. The 1630 and $1470 \mathrm{~cm}^{-1}$ bands, assigned to the $\nu C=C$ stretching modes of the A ring of flavan-3-ols, were not observable on the DP8 spectrum, likely because the intensity of these two modes occurs from the unlinked rings.

\subsection{CM5 immobilization and interaction analysis}

To obtain a good flexibility and subsequent binding site availability of immobilized flavanols, flavan-3-ols-SH were immobilized onto carboxymethyl dextran (CM5) sensor chips using a routine coupling method from GE Healthcare Life Sciences (Ligand thiol coupling, Laboratory guidelines BR-2001-21 AB). For this method, reactive disulfide groups were introduced into the dextran matrix then, the thiol coupling occurred through a thiol-disulfide exchange with the thiol groups on the ligand. EPI-SH, DP2-SH and DP8-SH were immobilized onto CM5 sensor chip with the following resonance units (312 RU, $417 \mathrm{RU}$ and $305 \mathrm{RU}$ respectively), then the excess reactive groups were deactivated with a $50 \mathrm{mM}$ cysteinecontaining $0.1 \mathrm{M}$ sodium acetate solution.

The modified sensor chips were first tested with a protein (BSA) and a polypeptide (PLP) well known to interact in solution with these flavan-3-ols $[9,11]$. Interactions between BSA and flavan-3ols depended on BSA concentrations. At $3 \mathrm{nM}$ BSA, the association step was higher with (-)-epicatechin ( $85 \mathrm{RU})$ than with dimer (34 RU) or oligomer DP8 (17 RU) (Fig. 2). For BSA concentration higher than $30 \mathrm{nM}$, the association step showed two stages that is an increase of association after the beginning of injection of BSA followed by a decrease of SPR signal after $1 \mathrm{~min}$ before the end of injection (data not shown). With poly-L-proline no interaction was detected at $3 \mathrm{nM}$ of peptide, while similar levels were obtained for all flavan-3-ols at $30 \mathrm{nM}$ of peptide (Table 3).

Only weak resonance units were obtained for apple pectins with either EPI or DP8 (around $15 \mathrm{RU}$ ), a slightly higher level being reached for DP2 (22 RU) whatever the concentrations of apple pectins (Fig. 3 and Table 3). Higher association was found with citrus pectin up to $120 \mathrm{RU}$ for all flavan-3-ols at the highest pectin concentration (Table 3).

\section{Discussion}

The binding affinity differences between flavan-3-ol derivatives immobilized onto CM5 surface and biomacromolecules might be explained either by the biomacromolecules or flavan-3-ol structure and conformation. On the one hand, BSA is composed of three domains and its tertiary structure (like an equilateral triangle)

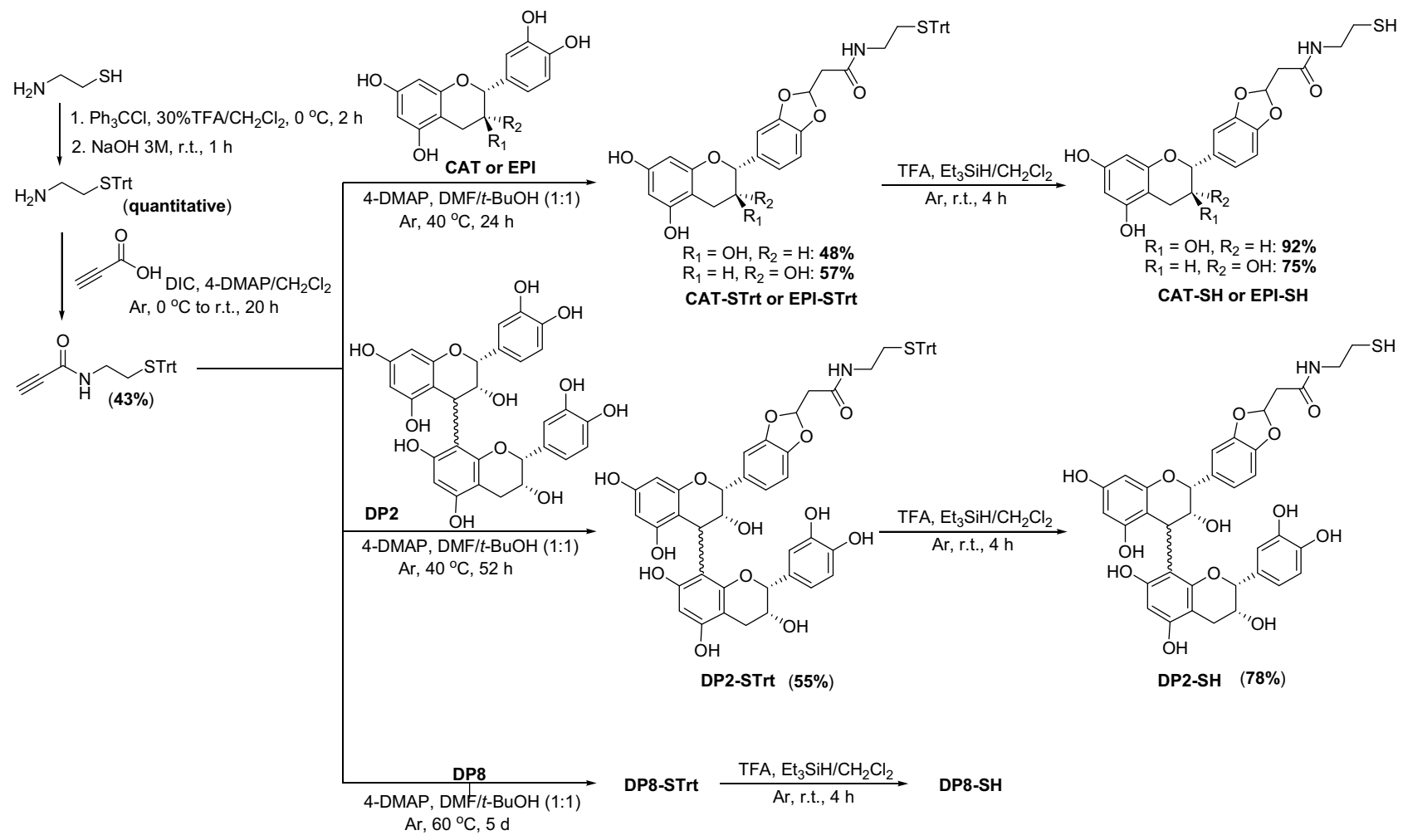

Scheme 1. Reaction scheme of chemical synthesis of $N-(2-[($ Triphenylmethylthio]ethyl) propiolamide linker and flavan-3-ols. 

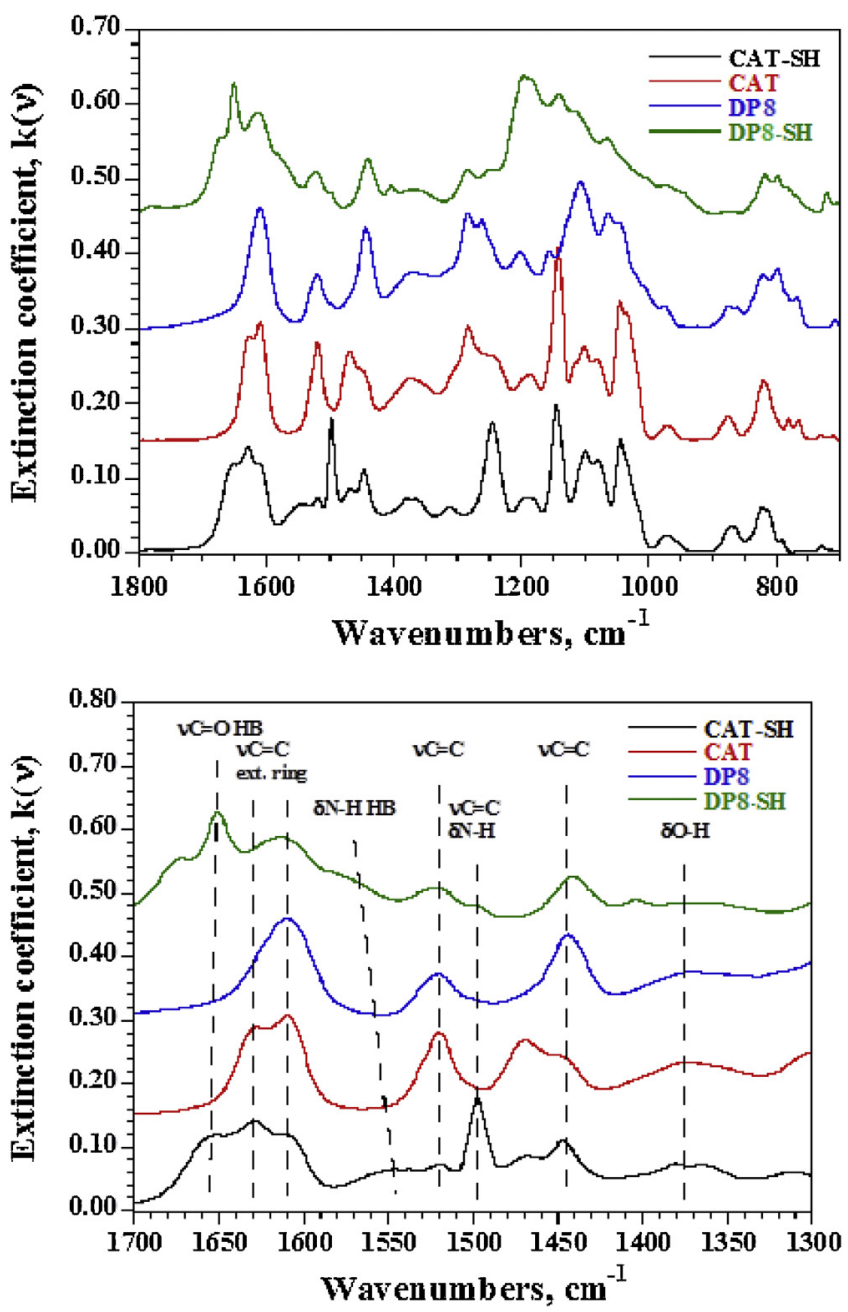

Fig. 1. Extinction coefficient spectra of $(+)$-catechin (CAT), (+)-catechin modified by linker with thiol group (CAT-SH), flavan-3-ol oligomer (DP8) and flavan-3-ol oligomer modified by linker with thiol group (DP8-SH). Assignment of the major bands in the $1700-1300 \mathrm{~cm}^{-1}$ spectral range.

is similar to Human Serum Albumin. Domains II and III form a positively charged hydrophobic cavity which allows for associations with ligands [27]. On the other hand, proline-rich proteins (PRPs), more precisely PLP, form an open extended structure which presents a maximum surface area for interaction per residue [28]. Therefore, we expected that the smaller polypeptide would bind more, as the steric hindrance should be limited (smaller molecule). The opposite was observed, perhaps due to limited flexibility (i.e. no possibility to adjust its conformation to the bound flavan-3-ols) [29] or due to involvement of the B-ring of the flavan-3-ols here modified and/or bound to the sensor chip, in the interaction.

Different response levels were observed between flavan-3-ols and the two pectins. Apple pectins showed higher resonance units with the dimer DP2 while citrus pectins interacted with more intensity but indifferently to the monomer, dimer and oligomer. Apple and citrus pectins differ by their neutral sugar composition, in particular by higher rhamnose and galactose in citrus pectins, i.e. presumably more type I rhamnogalacturonans. The high rhamnose content in apple pectins could induce an increase of the molecule flexibility and lead to a change of conformation [30]. Apart from rhamnose, neutral sugars tend to adopt various conformations in solution. Watrelot et al. [31] showed that $\beta-1 \rightarrow 4$ galactan chains bind more strongly to procyanidins than arabinan chains, and it was demonstrated that pectins with short neutral sugar side chains
Table 3

Resonance units corresponding to interactions between flavan-3-ols (-) epicatechin (EPI), dimer (DP2) and oligomer (DP8) and analytes (apple and citrus pectins, poly-L-proline and bovine serum albumin) at 3, 30 and $300 \mathrm{nM}$ in HBS-EP buffer at $25^{\circ} \mathrm{C}$.

\begin{tabular}{cccc}
\hline Analytes/Ligands & EPI (312 RU) & DP2 (417 RU) & DP8 (305 RU) \\
\hline Apple pectins & & & \\
$3 \mathrm{nM}$ & 16 & 22 & 14 \\
$30 \mathrm{nM}$ & 16 & 21 & 14 \\
$300 \mathrm{nM}$ & 11 & 15 & 10 \\
Citrus pectins & & & 61 \\
$3 \mathrm{nM}$ & 61 & 60 & 120 \\
$30 \mathrm{nM}$ & 118 & 119 & 119 \\
$300 \mathrm{nM}$ & 112 & & 17 \\
$3 \mathrm{nM}$ & & 34 & - \\
Bovine serum albumin & 85 & - & 58 \\
Poly-L-proline & & 64 & 65 \\
$3 \mathrm{nM}$ & - & 58 & \\
$30 \mathrm{nM}$ & 58 & & \\
$300 \mathrm{nM}$ & 61 & &
\end{tabular}

associate with flavan-3-ol polymers. This interaction would be due to a cooperative interaction between pectins and procyanidins.

Polyphenols were immobilized by the catechol group, which is the B-ring of flavan-3-ols. Consequently, for the monomer (i.e. (-)-epicatechin), the B-ring was not available to bind to biomacromolecules. Therefore, sensor chips prepared here could only detect interactions due either to hydrophobic interactions between Aor pyran C-ring and methyl groups of pectins or amino acids of proteins, or to hydrogen bonds between hydroxyl groups of Aand/or C-ring and hydroxyl groups of pectins or proteins, or both. The dimer DP2 was immobilized by one B-ring, which left the other free to interact. Therefore, the higher association of apple pectins with DP2 could be due to both parameters (conformation of apple pectins and a higher availability of binding sites of dimer). Regarding flavan-3-ol oligomers, the number of catechol groups immobilized was unknown and the conformation is fully different from that of monomer and dimer, notably with increased rigidity [32], while orientation with the respect to the surface remains unknown. Associations, both with pectins or proteins, were not correlated to the number of hydroxyl groups of polyphenols immobilized contrary to the work of Jean-Gilles et al. [33] but rather in the conformation adopted by polyphenols.

Associations between the same polyphenols and macromolecules (pectins and proteins) were recently measured in solution by Isothermal Titration Calorimetry (ITC) $[5,20]$. ITC is based upon heat exchange and measures the energy released upon (or necessary for) ligand-macromolecule interactions. Weak energies of interactions were found between pectins and flavan-3-ol monomers and dimers, so that method was not an appropriate method for measuring interactions parameters between those two molecules [5]. In contrast, SPR measurements showed that, depending on pectin concentrations, both pectins tend to interact more with the dimer than with the monomer. Therefore, provided or generated heat by interactions between pectins and flavan-3-ols monomer or dimer might be too low for detection, while the injection of pectins on a surface of $(-)$-epicatechin or dimer leads to formation of layers of pectins which induced a change of refracted light and also resonance units.

Associations between model proteins or polypeptides and flavan-3-ols were already measured by ITC [7,10-12,20]. ITC evidenced higher affinity of flavan-3-ol for BSA than for poly-L-proline as found here by SPR. This affinity increased with the increase of the degree of polymerization of flavan-3-ols, as previously observed [34]. However, in the case of immobilized flavan-3-ols (using SPR), affinity with BSA decreased with the increase of the DP. Moreover, degree of polymerization did not influence RU levels observed with poly-L-proline. As mentioned for analysis with pectins, impact of 


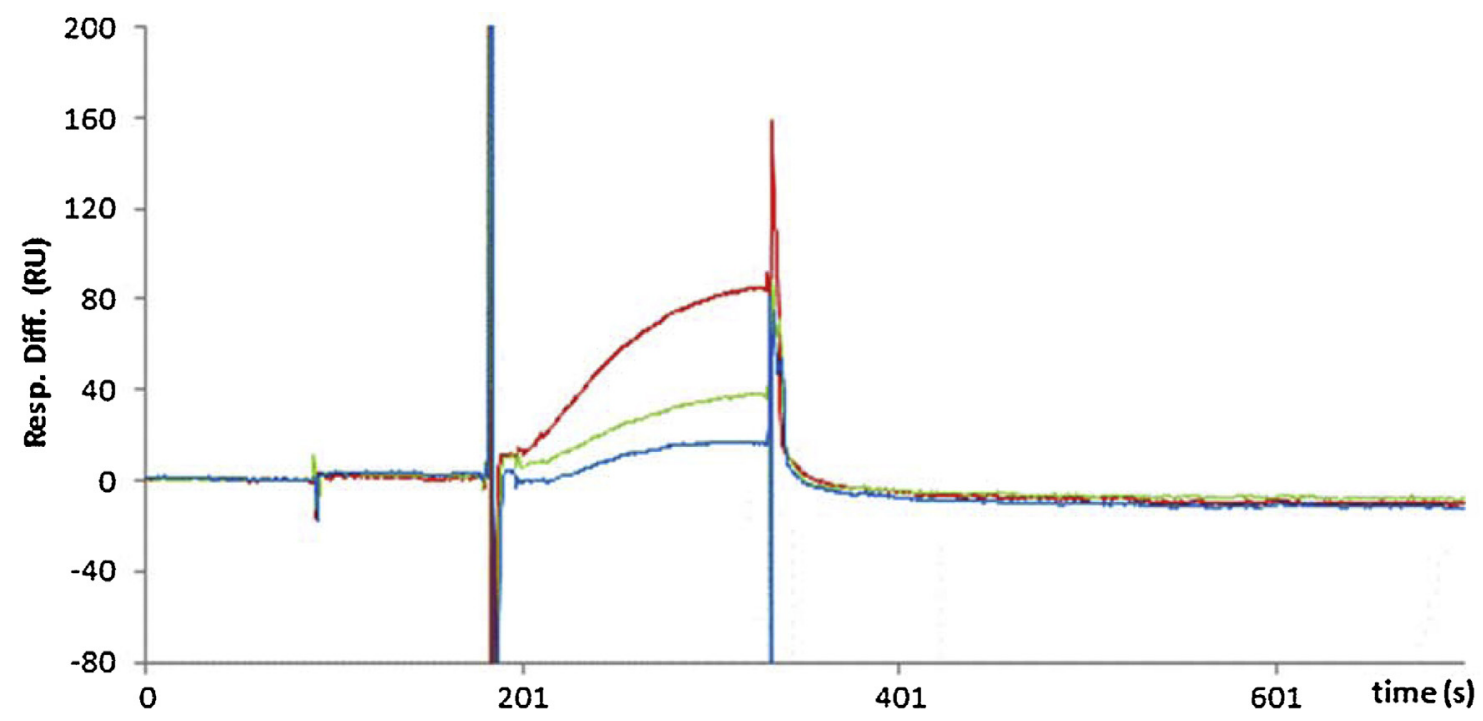

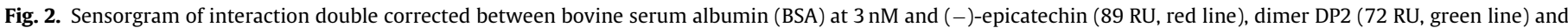

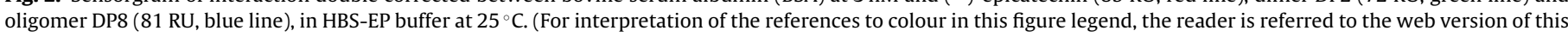
article.)

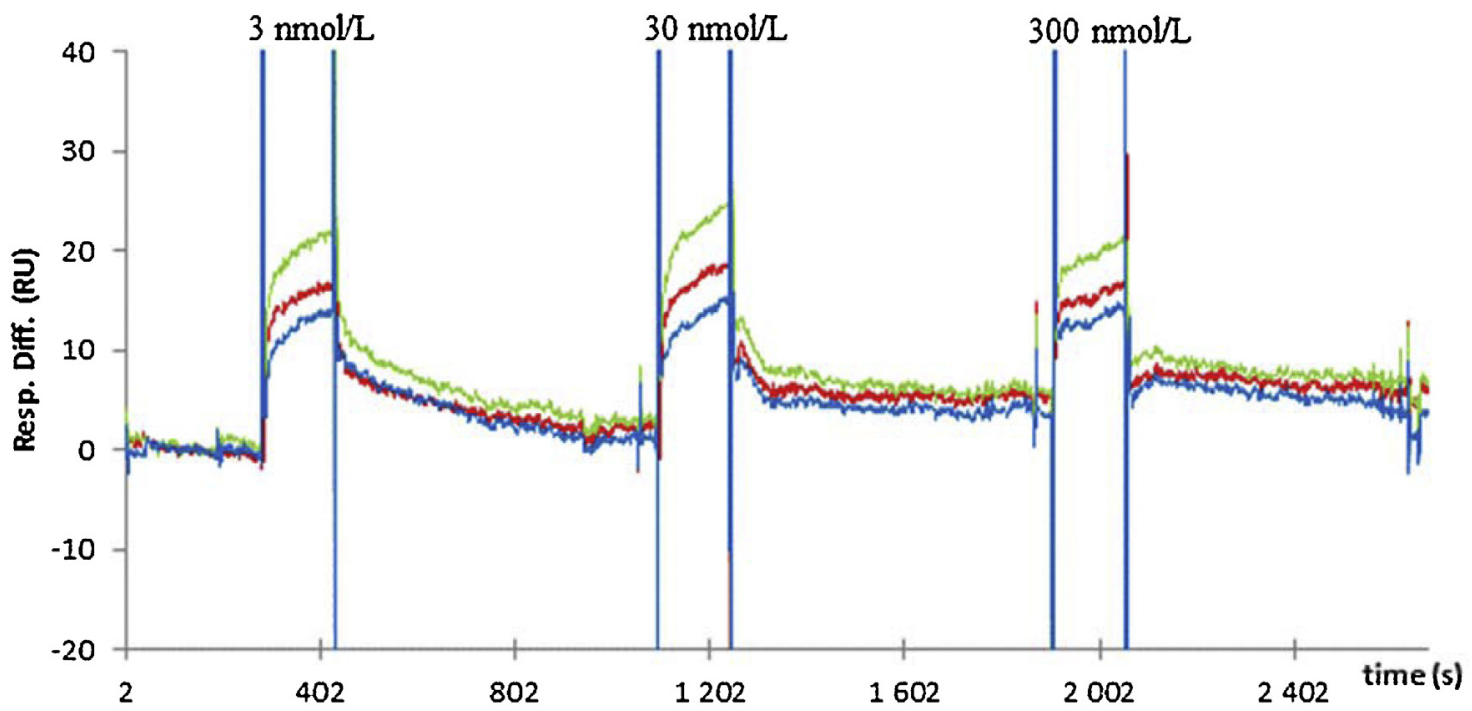

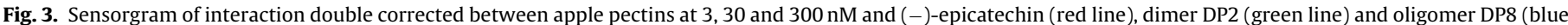
line) in HBS-EP buffer at $25^{\circ} \mathrm{C}$. (For interpretation of the references to colour in this figure legend, the reader is referred to the web version of this article.)

immobilization on flavan-3-ols conformation probably modified the interactions at the molecular level.

\section{Conclusions}

In this work, flavan-3-ol monomer, dimer and oligomer were chemically modified through their B-ring and for the first time grafted onto CM5 surface with success. The immobilization of flavan-3-ol derivatives onto a CM5 sensor chips, confirmed using SPR, allowed comparison of interactions of the same flavan-3-olbearing sensor chips with varied macromolecules, which brought new information on interaction characteristics. For the first time molecules of proteic and polysaccharidic nature were directly compared in the same system: though, as expected, higher affinities were obtained with BSA, citrus pectin in particular bound remarkably to the sensor chips. Therefore (i) interactions of flavan-3-ols with polysaccharides should not be neglected, particularly in plant food systems, and (ii) further work on the impact of fine structure of polysaccharides on the interactions with tannins is still needed. SPR analysis should be used in addition to ITC to compare the behavior of macromolecules when one is immobilized on a solid surface or both are in solution. This method is useful for a better understanding of the effect of the macromolecule conformation on associations. Because in this study the flavan-3-ols were immobilized onto a surface through B-rings and affinities were lower than obtained in solution, the results suggest that the flavan-3ol B-ring is involved in macromolecular interactions. This method gave new information about the interaction mechanisms occurring between macromolecules (condensed tannin, protein, polysaccharide), which are involved in astringency mouthfeel perception and colloids formation.

\section{Acknowledgments}

The authors thank Dr. Carmelo Di Primo for the use of his surface plasmon resonance equipment, and Dr. James A. Kennedy 
for manuscript review. The research leading to these results has received funding from the European Community's Seventh Framework Programme (FP7/2007-2013) under the grant agreement No. FP7-222654-DREAM.

\section{Appendix A. Supplementary data}

Supplementary data associated with this article can be found, in the online version, at http://dx.doi.org/10.1016/j.apsusc.2016.03. 002.

\section{References}

[1] J.M. McRae, J.A. Kennedy, Wine and grape tannin interactions with salivary proteins and their impact on astringency: a review of current research, Molecules 16 (3) (2011) 2348-2364.

[2] S. Quideau, D. Deffieux, C. Douat-Casassus, L. Pouységu, Plant polyphenols: chemical properties, biological activities, and synthesis, Angew. Chem. Int. Ed. 50 (3) (2011) 586-621.

[3] R.W. Hemingway, J.J. Karchesy, Chemistry and Significance of Condensed Tannins, Plenum Press, New York, 1989, pp. 553p.

[4] P. Sanoner, S. Guyot, N. Marnet, D. Molle, J.-F. Drilleau, Polyphenol profiles of french cider apple varieties (Malus Domestica Sp.), J. Agric. Food Chem. 47 (12) (1999) 4847-4853.

[5] A.A. Watrelot, C. Le Bourvellec, A. Imberty, C.M. Renard, Interactions between pectic compounds and procyanidins are influenced by methylation degree and chain length, Biomacromolecules 14 (2013) 709-718.

[6] B.L. Ridley, M.A. O'Neill, D. Mohnen, Pectins: structure, biosynthesis, and oligogalacturonide-related signaling, Phytochemistry 57 (6) (2001) 929-967.

[7] C. Poncet-Legrand, A. Edelmann, J.-L. Putaux, D. Cartalade, P. Sarni-Manchado, A. Vernhet, Poly(1-Proline) interactions with Flavan-3-Ols units: influence of the molecular structure and the polyphenol/protein ratio, Food Hydrocoll. 20 (5) (2006) 687-697

[8] C. Poncet-Legrand, C. Gautier, V. Cheynier, A. Imberty, Interactions between Flavan-3-Ols and Poly(1-Proline) studied by isothermal titration calorimetry: effect of the tannin structure, J. Agric. Food Chem. 55 (22) (2007) 9235-9240.

[9] C. Pascal, C. Poncet-Legrand, A. Imberty, C. Gautier, P. Sarni-Manchado, V. Cheynier, A. Vernhet, Interactions between a non glycosylated human proline-rich protein and flavan-3-ols are affected by protein concentration and polyphenol/protein ratio, J. Agric. Food Chem. 55 (12) (2007) 4895-4901.

[10] R.A. Frazier, A. Papadopoulou, I. Mueller-Harvey, D. Kissoon, R.J. Green, Probing protein-tannin interactions by isothermal titration microcalorimetry, J. Agric. Food Chem. 51 (18) (2003) 5189-5195.

[11] R.A. Frazier, A. Papadopoulou, R.J. Green, Isothermal titration calorimetry study of epicatechin binding to serum albumin, J. Pharm. Biomed. Anal. 41 (5) (2006) 1602-1605

[12] R.A. Frazier, E.R. Deaville, R.J. Green, E. Stringano, I. Willoughby, J. Plant, I Mueller-Harvey, Interactions of tea tannins and condensed tannins with proteins, J. Pharm. Biomed. Anal. 51 (2) (2010) 490-495.

[13] G. Gyémánt, Á. Zajácz, B. Bécsi, C. Ragunath, N. Ramasubbu, F. Erdődi, G. Batta, L. Kandra, Evidence for pentagalloyl glucose binding to human salivary $\alpha$-amylase through aromatic amino acid residues, Biochim. Biophys. Acta BBA-Proteins Proteom. 1794 (2) (2009) 291-296.

[14] J.R.L. Guerreiro, V. De Freitas, D.S. Sutherland, M.G.F. Sales, SPR based studies for pentagalloyl glucose binding to $\alpha$-amylase, Procedia Eng. 47 (2012) 498-501.

[15] A. Kiss, B. Bécsi, B. Kolozsvári, I. Komáromi, K.E. Kövér, F. Erdődi, Epigallocatechin-3-gallate and penta-O-galloyl- $B$-D-glucose inhibit protein phosphatase-1, FEBS J. 280 (2) (2013) 612-626.
[16] S. Quideau, C. Douat-Casassus, D.M. Delannoy López, C. Di Primo, S. Chassaing R. Jacquet, F. Saltel, E. Genot, Binding of filamentous actin and winding into fibrillar aggregates by the polyphenolic c-glucosidic ellagitannin vescalagin, Angew. Chem. Int. Ed. 50 (22) (2011) 5099-5104.

[17] L. Joergensen, B. Klösgen, A.C. Simonsen, J. Borch, E. Hagesaether, New insights into the mucoadhesion of pectins by AFM roughness parameters in combination with SPR, Int. J. Pharm. 411 (1-2) (2011) 162-168.

[18] J.H. Seo, K. Adachi, B.K. Lee, D.G. Kang, Y.K. Kim, K.R. Kim, H.Y. Lee, T. Kawai, H.J. Cha, Facile and rapid direct gold surface immobilization with controlled orientation for carbohydrates, Bioconjugate Chem. 18 (6) (2007) 2197-2201.

[19] N. Hayashi, R. Chen, M. Hiraoka, T. Ujihara, H. Ikezaki, B-cyclodextrin/surface plasmon resonance detection system for sensing bitter-astringent taste intensity of green tea catechins, J. Agric. Food Chem. 58 (14) (2010) $8351-8356$

[20] A.A. Watrelot, C.M.G.C. Renard, C. Le Bourvellec, Comparison of microcalorimetry and haze formation to quantify the association of b-type procyanidins to poly-L-proline and bovine serum albumin, LWT-Food Sci. Technol. 63 (1) (2015) 376-382.

[21] R. Liu, R. Liew, J. Zhou, B. Xing, A simple and specific assay for real-time colorimetric visualization of $\beta$-lactamase activity by using gold nanoparticles, Angew. Chem. Int. Ed. 46 (46) (2007) 8799-8803.

[22] H.-Y. Shiu, T.-C. Chan, C.-M. Ho, Y. Liu, M.-K. Wong, C.-M. Che Electron-deficient alkynes as cleavable reagents for the modification of cysteine-containing peptides in aqueous medium, Chem. Weinh. Bergstr. Ger. 15 (15) (2009) 3839-3850.

[23] X. Ariza, O. Pineda, J. Vilarrasa, G.W. Shipps Jr., Y. Ma, X. Dai, Bocdene and mocdene derivatives of catechols and catecholamines, Org. Lett. 3 (9) (2001) 1399-1401.

[24] H. Basit, A. Van der Heyden, C. Gondran, B. Nysten, P. Dumy, P. Labbé, Tethered bilayer lipid membranes on mixed self-assembled monolayers of a novel anchoring thiol: impact of the anchoring thiol density on bilayer formation, Langmuir ACS J. Surf. Colloids 27 (23) (2011) 14317-14328.

[25] M.J. Dignam, Fourier transform polarization spectroscopy, Appl. Spectrosc. Rev. $24(1-2)(1988)$ 99-135.

[26] C. Chalumeau, D. Deffieux, S. Chaignepain, S. Quideau, Development of an affinity-based proteomic strategy for the elucidation of proanthocyanidin biosynthesis, ChemBioChem 12 (8) (2011) 1193-1197.

[27] S. Sugio, A. Kashima, S. Mochizuki, M. Noda, K. Kobayashi, Crystal structure of human serum albumin at 2.5 Å resolution, Protein Eng. 12 (6) (1999) 439-446.

[28] M.P. Williamson, The structure and function of proline-rich regions in proteins, Biochem. J. 297 (2) (1994) 249-260

[29] T. Richard, X. Vitrac, J.M. Merillon, J.P. Monti, Role of peptide primary sequence in polyphenol-protein recognition: an example with neurotensin, Biochim. Biophys. Acta 1726 (3) (2005) 238-243.

[30] C.M.G.C. Renard, M.-J. Crépeau, J.-F. Thibault, Structure of the repeating units in the rhamnogalacturonic backbone of apple: beet and citrus pectins Carbohydr. Res. 275 (1) (1995) 155-165.

[31] A.A. Watrelot, C. Le Bourvellec, A. Imberty, C.M. Renard, Neutral sugar side chains of pectins limit interactions with procyanidins, Carbohydr. Polym. 99 (2014) 527-536

[32] D. Zanchi, P.V. Konarev, C. Tribet, A. Baron, D.I. Svergun, S. Guyot, Rigidity, conformation, and solvation of native and oxidized tannin macromolecules in water-ethanol solution, J. Chem. Phys. 130 (24) (2009).

[33] D. Jean-Gilles, L. Li, V.G. Vaidyanathan, R. King, B. Cho, D.R. Worthen, Chichester III, C.O.: seeram, N.P. inhibitory effects of polyphenol punicalagin on type-ii collagen degradation in vitro and inflammation in vivo, Chem. Biol. Interact. 205 (2) (2013) 90-99.

[34] R.L. Kilmister, P. Faulkner, M.O. Downey, S.J. Darby, R.J. Falconer, The complexity of condensed tannin binding to bovine serum albumin-an isothermal titration calorimetry study, Food Chem. 190 (2016) 173-178. 